\title{
Colonoscopic factors associated with adenoma detection in a national colorectal cancer screening program
}

Authors

Institutions
Thomas J. W. Lee' ${ }^{1}$, Colin J. Rees ${ }^{3,4,5}$, Roger G. Blanks ${ }^{6}$, Sue M. Moss ${ }^{7}$, Claire Nickerson ${ }^{8}$, Karen C. Wright ${ }^{7}$, Peter W. James ${ }^{2}$, Richard J. Q. McNally ${ }^{2}$, Julietta Patnick ${ }^{8}$, Matthew D. Rutter ${ }^{1,4,5}$

Institutions are listed at the end of article. submitted 23. March 2013 accepted after revision 30. September 2013

\section{Bibliography}

Dol http://dx.doi.org/ 10.1055/s-0033-1358831 Published online: 28.1.2014 Endoscopy 2014; 46: 203-211 (c) Georg Thieme Verlag KG Stuttgart · New York ISSN 0013-726X

Corresponding author Thomas J. W. Lee, MD 4th Floor Sir James Spence Institute Royal Victoria Infirmary Queen Victoria Road Newcastle-upon-Tyne, NE1 4LP UK

Fax: +44-1642-383289

Tomlee@doctors.org.uk
Background and study aims: Adenoma detection is a key objective of colonoscopy, particularly in the context of colorectal cancer screening. The aim of this observational study was to identify the technical colonoscopy factors associated with adenoma detection.

Patients and methods: The study analyzed data from the English Bowel Cancer Screening Programme. The indication for all colonoscopies was a positive fecal occult blood test. The relationships between the following colonoscopy factors and adenoma detection (one or more adenomas, advanced adenomas, right-sided adenomas, and total number of adenomas) were examined in multivariable analyses: bowel preparation quality, cecal intubation, withdrawal time, rectal retroversion, colonoscopist experience, antispasmodic use, sedation use, and start time of procedure. The following patient factors were controlled for: age, sex, body mass index, smoking, alcohol, deprivation, and geographical location.

\section{Introduction}

\section{$\nabla$}

Colorectal cancer (CRC) is the second most common cause of cancer death in the United Kingdom [1]. The majority of CRCs develop from adenomas [2]. Adenoma detection is therefore a key objective of colonoscopy. Adenoma detection rate (ADR) is widely regarded as one of the key performance indicators of colonoscopy [3]. Increasing ADR has been shown to correlate with decreased interval cancer rate [4].

Multiple factors may affect whether an adenoma is detected during colonoscopy. These may be patient factors such as male sex, increasing age, cigarette smoking, and alcohol use [5-9].

This study focused on the colonoscopy factors (many of which relate to the completeness of pancolonic mucosal inspection) that determine whether adenomas are detected. Cecal intubation, colonoscopy withdrawal time, and bowel
Results: A total of 31088 colonoscopies were analyzed. The following technical factors increased the relative risk of adenoma detection $(P<0.001$ in multivariable analysis unless otherwise stated): cecal intubation, increased withdrawal time, higher quality bowel preparation, intravenous antispasmodic use, earlier procedure start time within a session $(P=0.018)$, and greater colonoscopist experience. Detection of advanced and right-sided adenomas also increased with these factors. Adenoma detection did not differ between sedated and unsedated colonoscopy $(P=$ 0.143).

Conclusion: This study demonstrated important associations between colonoscopy practice and adenoma detection. Use of intravenous antispasmodic was associated with increased adenoma detection. The effect of the start time of colonoscopy suggests that endoscopist fatigue may have a deleterious impact on adenoma detection.

preparation quality have been shown to be associated with increased adenoma detection [1016]. Other technical factors, such as intravenous antispasmodic use, rectal retroversion, start time of the procedure, and sedation practice, have been postulated as affecting adenoma detection with conflicting findings in studies to date [1726]. These factors are important as they are modifiable by the colonoscopist, offering the opportunity to optimize adenoma detection, and may reduce future cancer risk.

Intravenous antispasmodics, such as hyoscine $\mathrm{N}$ butylbromide, relax smooth muscle in the colon, minimizing haustral definition and theoretically reducing the amount of mucosa not visible to a forward-viewing colonoscope. Recent studies have produced conflicting findings on the effect of hyoscine on adenoma detection [17-20]. Few previous studies of technical aspects of colonoscopy have included the full range of currently 
known, measurable technical variables of colonoscopy in addition to patient factors, to examine the likelihood of adenomas being detected. This approach is necessary to allow for confounding between potential risk factors and enables known risk factors for neoplasia to be controlled for while examining the role of potentially modifiable aspects of colonoscopy practice.

The English Bowel Cancer Screening Programme (BCSP) was chosen as the setting for this study as it provides a population undergoing colonoscopy for a consistent indication (positive fecal occult blood test) with a prospectively collected comprehensive dataset [27]. In addition, quality assurance processes are built in to the BCSP to ensure that detailed data on patients and procedures are prospectively collected, and colonoscopists practising in the program are required to meet stringent selection criteria and maintain ongoing high standards of performance [28].

The aim of this study was to identify colonoscopy technical factors associated with increased or decreased risk of adenoma detection.

\section{Patients and methods \\ $\nabla$}

\section{Study population}

The English BCSP offers biennial nonrehydrated guaiac-based fecal occult blood test (FOBT) to individuals in England aged 60 - 69 years (the upper age limit was extended to 74 in 2010). Individuals with a positive FOBT are offered colonoscopy [29]. Prior to commencing practice in the BCSP, all colonoscopists are required to undergo a comprehensive accreditation process. Accredited colonoscopists are then subject to ongoing audit of colonoscopic performance [28].

All colonoscopies in the BCSP between August 2006 and August 2009 were studied. The indication for all procedures was a positive FOBT. Surveillance colonoscopies were excluded from analysis, and in cases where an individual had more than one procedure in a screening episode, only the first procedure was included in order to avoid double-counting of adenomas. Demographic, colonoscopic, and histological data were prospectively collected and collated centrally in the Bowel Cancer Screening System (BCSS) database.

Demographic and lifestyle data (date of birth, sex, smoking status, alcohol consumption, height in metres, weight in $\mathrm{kg}$, postal code) were prospectively collected from individuals prior to colonoscopy during a pre-colonoscopy assessment with a trained screening practitioner.

\section{Study procedures}

Data downloaded from the BCSS database were checked for completeness and plausibility. When possible, missing data were retrieved from the screening center. Completeness of data was validated by cross checking with local data sources. Data entries for continuous variables (height, weight, drug doses, and withdrawal time) that were considered implausible by panel decision were excluded from further analysis. These data cleaning processes are described in further detail in a previous publication [28].

Colonoscopy data recorded at the time of the procedure included cecal intubation (as evidenced by anatomical landmarks), withdrawal time (defined as the time taken to withdraw the colonoscope from the cecum to the anus), rectal retroversion, sedative medication or intravenous antispasmodic (hyoscine N-butylbromide) use, and quality of bowel preparation. Bowel preparation quality was recorded on a four-point scale. Descriptors for bowel preparation quality were: incomplete examination due to inadequate preparation; complete examination despite inadequate preparation; adequate or excellent preparation [30].

Mean colonoscopy withdrawal times were calculated for each colonoscopist for negative complete procedures only (nc-CWT). Use of actual withdrawal times for individual procedures is not appropriate as it is influenced by the duration of therapeutic procedures rather than time spent examining the colonic mucosa during withdrawal [13]. Mean nc-CWT per colonoscopist were further dichotomized into two groups ( $<10$ minutes, $\geq 10$ minutes) based on a previous study suggesting that colonoscopists with mean nc-CWT $\geq 10$ minutes tended to have higher ADR than those with shorter mean withdrawal times [13]. A cut-off time of 6 minutes was not used in this analysis as only $15 \%$ of colonoscopists had a mean withdrawal time below this threshold and no clinically significant relationship between ADR and mean ncCWT were observed with this cut-off in univariable analysis. Exploratory analysis with nc-CWT as a continuous variable did not affect the findings.

Exploratory analysis of start time of procedure suggested a relationship between how early in the morning or afternoon session the procedure was commenced and adenoma detection. Procedure start time was therefore divided into two groups. In one group, the procedure commenced in the first half of a session (08:00-11:00 or 14:00-16:00); the second group consisted of procedures starting in the second half of the session (11:0014:00 or 16:00-18:00).

All colonoscopists in the BCSP had completed at least 1000 procedures during their career prior to obtaining accreditation to commence screening colonoscopy. To account for colonoscopist experience of colonoscopy in the screening program, procedures were grouped into those among the first 300 procedures performed by an individual colonoscopist in the screening program and subsequent procedures. The cut-off at 300 procedures per colonoscopist was determined by exploratory analysis, which showed no significant relationship when groups of 100 or 200 procedures were used.

Finally, procedures were assigned to a group depending on whether intravenous sedative/analgesic medication was used or the procedure was performed unsedated. The use of sedative medication or intravenous antispasmodic medication was at the discretion of the colonoscopist and patient.

Patient age was recorded on the date of colonoscopy. Age was analyzed as a categorical variable $(<62.5,62.5-64.9,65.0-$ $67.49, \geq 67.5$ years) to aid interpretation of results. Smoking status was categorized as current smoker, ex-smoker or never smoked. Alcohol use was dichotomized as either current use or not. Body mass index (BMI, $\mathrm{kg} / \mathrm{m}^{2}$ ) was calculated from self-reported height and weight measurements and grouped into two categories ( $<25.0$ and $\geq 25.0 \mathrm{~kg} / \mathrm{m}^{2}$ ). Deprivation scores (a measure of the socioeconomic status of the individual) were assigned using an individual's postal code at the time of entry to the screening program. Postal codes were linked to the Index of Multiple Deprivation scores (IMD) at the Lower Super Output Area level. In subsequent analysis the IMD scores of the study population were ranked in quintiles from highest to lowest deprivation scores, where group 1 was the most deprived and group 5 the least deprived [31].

The BCSP is coordinated by five hubs, which are responsible for inviting individuals for the FOBT. The hub in which the individual lived at the time of invitation to the screening program was included in the study as a geographical variable. 
Table 1 Univariable analysis demonstrating relationships between patient characteristics and proportions of patients with one or more adenomas, advanced adenomas, and right-sided adenomas.

\begin{tabular}{|c|c|c|c|c|c|c|c|}
\hline Patient characteristics & $\begin{array}{l}\text { Patients (n=31 } \\
088), n(\%)\end{array}$ & $\begin{array}{l}\text { Patients with } \geq 1 \\
\text { adenoma }(n= \\
14423), n(\%)^{1}\end{array}$ & $P$ & $\begin{array}{l}\text { Patients with } \geq 1 \\
\text { advanced adeno- } \\
\text { ma ( } n=8985) \text {, } \\
n(\%)^{1}\end{array}$ & $P$ & $\begin{array}{l}\text { Patients with } \geq 1 \\
\text { right-sided ade- } \\
\text { noma ( } \mathrm{n}=5999 \text { ), } \\
\mathrm{n}(\%)^{1}\end{array}$ & $P$ \\
\hline \multicolumn{8}{|l|}{ Sex } \\
\hline Female & $12327(39.7)$ & $4505(36.5)$ & \multirow[t]{2}{*}{$<0.001$} & $2737(22.2)$ & \multirow[t]{2}{*}{$<0.001$} & $1614(13.1)$ & \multirow[t]{2}{*}{$<0.001$} \\
\hline Male & $18761(60.3)$ & 9918 (52.9) & & $6248(33.3)$ & & $4385(23.4)$ & \\
\hline \multicolumn{8}{|l|}{ Age, years } \\
\hline$<62.5$ & $8415(27.1)$ & $3644(43.3)$ & \multirow[t]{4}{*}{$<0.001$} & $2273(27.0)$ & \multirow[t]{4}{*}{$<0.001$} & $1418(16.9)$ & \multirow[t]{4}{*}{$<0.001$} \\
\hline $62.5-64.9$ & $4959(16.0)$ & $2235(45.1)$ & & $1351(27.2)$ & & $954(19.2)$ & \\
\hline $65-67.49$ & $6844(22.0)$ & 3181 (46.5) & & $2009(29.4)$ & & $1322(19.3)$ & \\
\hline$\geq 67.5$ & $10870(35.0)$ & $5363(49.3)$ & & $3352(30.8)$ & & $2305(21.2)$ & \\
\hline \multicolumn{8}{|l|}{ Smoking ${ }^{2}$} \\
\hline Never & $17039(54.8)$ & $7280(42.7)$ & \multirow[t]{3}{*}{$<0.001$} & $4481(26.3)$ & \multirow[t]{3}{*}{$<0.001$} & $2937(17.2)$ & \multirow[t]{3}{*}{$<0.001$} \\
\hline Ex-smoker & $10344(33.3)$ & $5145(49.7)$ & & $3323(32.1)$ & & $2138(20.7)$ & \\
\hline Current smoker & $3517(11.3)$ & $1923(54.7)$ & & $1136(32.3)$ & & $891(25.3)$ & \\
\hline \multicolumn{8}{|l|}{ Alcohol $^{3}$} \\
\hline No & $10422(33.5)$ & $4069(39.0)$ & \multirow[t]{2}{*}{$<0.001$} & $2363(22.7)$ & \multirow[t]{2}{*}{$<0.001$} & $1596(15.3)$ & \multirow[t]{2}{*}{$<0.001$} \\
\hline Yes & $20364(65.5)$ & $10233(50.3)$ & & $6547(32.1)$ & & $4349(21.4)$ & \\
\hline \multicolumn{8}{|l|}{$\mathrm{BMI}^{4}, \mathrm{~kg} / \mathrm{m}^{2}$} \\
\hline$<25.0$ & $6588(21.2)$ & $3020(45.8)$ & \multirow[t]{2}{*}{0.179} & $1869(28.4)$ & \multirow[t]{2}{*}{0.226} & $1249(19.0)$ & \multirow[t]{2}{*}{0.376} \\
\hline$\geq 25.0$ & $19413(62.4)$ & $9085(46.8)$ & & $5660(29.2)$ & & $3778(19.5)$ & \\
\hline \multicolumn{8}{|l|}{ Deprivation Group ${ }^{5}$} \\
\hline 1 (most deprived quintile) & $6215(20.0)$ & $2765(44.5)$ & \multirow[t]{5}{*}{$<0.001$} & $1620(26.1)$ & \multirow[t]{5}{*}{$<0.001$} & $1201(19.3)$ & \multirow[t]{5}{*}{0.909} \\
\hline 2 & $6216(20.0)$ & $2837(45.6)$ & & $1703(27.4)$ & & $1226(19.7)$ & \\
\hline 3 & $6217(20.0)$ & $2876(46.3)$ & & $1781(28.6)$ & & $1189(19.1)$ & \\
\hline 4 & $6217(20.0)$ & $2933(47.2)$ & & $1888(30.4)$ & & $1192(19.2)$ & \\
\hline 5 (least deprived quintile) & $6207(20.0)$ & $3005(48.4)$ & & $1989(32.0)$ & & $1188(19.1)$ & \\
\hline \multicolumn{8}{|l|}{ Hub area } \\
\hline Midlands & $9369(30.1)$ & $4191(44.7)$ & \multirow[t]{5}{*}{$<0.001$} & $2601(27.8)$ & \multirow[t]{5}{*}{$<0.001$} & $1726(18.4)$ & \multirow[t]{5}{*}{$<0.001$} \\
\hline South & $5633(18.1)$ & $2740(48.6)$ & & $1764(31.3)$ & & $1056(18.7)$ & \\
\hline London & $4636(14.9)$ & $1966(42.4)$ & & 1107 (23.9) & & $976(21.1)$ & \\
\hline North-East & $4864(15.6)$ & $2375(48.8)$ & & $1540(31.7)$ & & $905(18.6)$ & \\
\hline Eastern & $6586(21.2)$ & $3151(47.8)$ & & $1973(30.0)$ & & $1336(20.3)$ & \\
\hline
\end{tabular}

BMI, body mass index.

${ }^{1}$ Calculated as a percentage of the respective patient characteristics.

2 Smoking status of patient not known for 188 procedures $(0.60 \%)$.

${ }^{3}$ Alcohol usage of patient not known for 302 procedures $(0.97 \%)$.

${ }^{4} \mathrm{BMl}$ of patient not known for 5807 procedures (18.7\%).

${ }^{5}$ Postcode (and deprivation index) of patient not known for 16 procedures $(0.05 \%)$.

The number, location, size, and histological grade of each adenoma detected during colonoscopy were recorded. This allowed colonoscopies to be classified according to the following outcomes: one or more adenomas detected, one or more advanced adenomas detected (defined as adenomas $\geq 1 \mathrm{~cm}$ in size or displaying high grade dysplasia or polyp cancer), one or more right-sided adenomas (lesions at or proximal to the splenic flexure), and one or more rectal adenomas detected. Only lesions that were histologically confirmed as adenomas were counted; these included, tubular, tubulovillous, villous, and serrated adenomas. In addition, the total number of adenomas detected at each procedure was recorded.

Approval of this study as service evaluation was obtained from a Regional Ethics Committee.

\section{Statistical analysis}

Normally distributed continuous variables are presented as mean $( \pm S D)$. Categorical variables are presented as total proportions and percentages ( $\mathrm{n}, \%)$. Univariable analysis was performed using the chi-squared test for comparison of categorical variables and the unpaired $t$ test for continuous variables. This exploratory testing identified variables that were associated with the presence of one or more adenomas. The procedure was repeated to identify variables associated with the presence of one or more advanced adenomas, right-sided adenomas, and rectal adenomas. In order to allow for confounding between variables, multivariable analysis using binary logistic regression to calculate odds ratios (OR) with $95 \%$ confidence intervals $(\mathrm{CI})$ was performed. Four separate models (with $\geq 1$ adenoma, $\geq 1$ advanced adenoma, $\geq 1$ right-sided adenoma, and $\geq 1$ rectal adenoma as the dependent variables) were analyzed using the forward stepwise logistic regression approach.

The following patient variables were tested: sex, age, smoking status, alcohol use, BMI category, deprivation quintile, hub area. The following colonoscopy variables were tested: cecal intubation, rectal retroversion, colonoscopist mean nc-CWT group, bowel preparation quality, hyoscine use, procedure start time group, colonoscopist experience group, and intravenous sedation group.Variables were included in the multivariable models if they reached a significance level of $P \leq 0.1$ in univariable testing. 
Table 2 Univariable analysis demonstrating relationships between colonoscopy characteristics and proportions of patients with one or more adenomas, advanced adenomas, and right-sided adenomas.

\begin{tabular}{|c|c|c|c|c|c|c|c|}
\hline Colonoscopy characteristics & $\begin{array}{l}\text { Patients ( } \mathrm{n}= \\
31 \text { 088), n (\%) }\end{array}$ & $\begin{array}{l}\text { Patients with } \\
\geq 1 \text { adenoma } \\
\text { ( } n=14423 \text { ), } \\
n(\%)^{1}\end{array}$ & $P$ & $\begin{array}{l}\text { Patients with } \\
\geq 1 \text { advanced } \\
\text { adenoma } \\
(\mathrm{n}=8985) \\
\mathrm{n}(\%)^{1}\end{array}$ & $P$ & $\begin{array}{l}\text { Patients with } \\
\geq 1 \text { right-sided } \\
\text { adenoma ( }= \\
\text { 5999), } n(\%)^{1}\end{array}$ & $P$ \\
\hline \multicolumn{8}{|l|}{ Cecal Intubation } \\
\hline No & $1365(4.4)$ & $244(17.9)$ & $<0.001$ & $151(11.1)$ & $<0.001$ & $57(4.2)$ & $<0.001$ \\
\hline Yes & $29723(95.6)$ & $14179(47.7)$ & & $8834(29.7)$ & & $5942(20.0)$ & \\
\hline \multicolumn{8}{|l|}{ Rectal retroversion } \\
\hline No & $3115(10.0)$ & $1433(46.0)$ & 0.645 & $1001(32.1)$ & $<0.001$ & $589(18.9)$ & 0.581 \\
\hline Yes & $27973(90.0)$ & $12990(46.4)$ & & $7984(28.5)$ & & $5410(19.3)$ & \\
\hline \multicolumn{8}{|l|}{$\begin{array}{l}\text { Colonoscopist mean nc-CWT, } \\
\text { minutes }\end{array}$} \\
\hline$<10$ & $19816(63.7)$ & $9020(45.5)$ & $<0.001$ & $5769(29.1)$ & 0.280 & $3609(18.2)$ & $<0.001$ \\
\hline$\geq 10$ & $11272(36.3)$ & $5403(47.9)$ & & $3216(28.5)$ & & $2390(21.2)$ & \\
\hline \multicolumn{8}{|l|}{ Bowel preparation quality ${ }^{2}$} \\
\hline Inadequate preparation & $1637(5.3)$ & $620(37.9)$ & $<0.001$ & $360(22.0)$ & $<0.001$ & $277(16.9)$ & 0.011 \\
\hline Excellent or adequate & $29280(94.2)$ & $13775(47.0)$ & & $8610(29.4)$ & & $5708(19.5)$ & \\
\hline \multicolumn{8}{|l|}{ Antispasmodic use } \\
\hline No & $20521(66.0)$ & $9129(44.5)$ & $<0.001$ & $5629(27.4)$ & $<0.001$ & $3718(18.1)$ & $<0.001$ \\
\hline Yes & $10567(34.0)$ & $5294(50.1)$ & & $3356(31.8)$ & & $2281(21.6)$ & \\
\hline \multicolumn{8}{|l|}{ Start time of procedure ${ }^{3}$} \\
\hline $08: 00-11: 00$ or $14: 00-16: 00$ & $19635(63.2)$ & $9244(47.1)$ & 0.010 & $5810(29.6)$ & 0.003 & $3857(19.6)$ & 0.125 \\
\hline $11: 00-14: 00$ or $16: 00-18: 00$ & $9790(31.5)$ & $4453(45.5)$ & & $2732(27.9)$ & & $1849(18.9)$ & \\
\hline \multicolumn{8}{|c|}{ Prior colonoscopist experience in the BCSP (number of procedures) } \\
\hline $0-299$ & $27844(89.6)$ & $12858(46.2)$ & 0.027 & $7972(28.6)$ & 0.002 & $5290(19.0)$ & $<0.001$ \\
\hline$\geq 300$ & $3244(10.4)$ & $1565(48.2)$ & & $1013(31.2)$ & & $709(21.9)$ & \\
\hline \multicolumn{8}{|l|}{ Sedation } \\
\hline Used & $27012(86.9)$ & $12422(46.0)$ & $<0.001$ & $7750(28.7)$ & 0.036 & $5149(19.1)$ & 0.007 \\
\hline Not used & $4076(13.1)$ & $2001(49.1)$ & & $1235(30.3)$ & & $850(20.9)$ & \\
\hline
\end{tabular}

nc-CWT, Mean negative complete colonoscopy withdrawal time; BCSP, Bowel Cancer Screening Programme

${ }^{1}$ Calculated as a percentage of the respective colonoscopy characteristics.

2 Bowel preparation quality not known for 171 procedures.

${ }^{3}$ Start time not known or not valid for 1663 procedures (5.3\%).

A similar approach using an ordinal regression model was used to examine the relationship between patient and colonoscopy factors and the total number of adenomas detected. The Pearson chi-squared test was used to assess goodness of fit of models (a $P$ value $>0.05$ suggested the model fits adequately). All reported $P$ values are two sided, and a $P$ value of less than 0.05 was considered significant. Analyses were undertaken using SPSS version 17.0 (SPSS Inc., Chicago, Illinois, USA).

\section{Results}

Patient and procedure characteristics

A total of 31088 FOBT-positive colonoscopies were analyzed. These were performed by 148 colonoscopists. A total of 18761 $(60.3 \%)$ procedures involved male patients. The mean $( \pm S D)$ age of patients was $65.8 \pm 3.75$ years. One or more adenomas were detected in 14423 of 31088 procedures (46.4\%). One or more advanced adenomas were detected in 8985 procedures (28.9\%). One or more right-sided adenomas were detected in 5999 procedures (19.2\%). The mean number of adenomas detected per procedure was $0.91 \pm 0.25$.

Demographic and lifestyle characteristics of the study population are shown in Table 1 with univariable analyses for each of the outcome variables.
- Table 2 shows colonoscopy factors and univariable associations with each outcome variable. Cecal intubation (unadjusted) was achieved in $95.6 \%$ of procedures and was significantly associated with increased detection of one or more adenomas, advanced adenomas, and right-sided adenomas (all $P<0.001$ ). Rather than exclude incomplete procedures from multivariable analysis, this variable was included in the logistic regression to adjust for cecal intubation. Rectal retroversion was not associated with detection of adenomas or right-sided adenomas $(P=0.645$ and 0.581 , respectively), and was performed in fewer patients with one or more advanced adenomas ( $28.5 \%$ vs. $32.1 \%$; $P<0.001)$. Further analysis was performed to examine the effect of rectal retroversion on rectal adenoma detection. In 27973 procedures where rectal retroversion was performed, one or more rectal adenomas were detected in 2523 procedures (9.0\%). In comparison, one or more rectal adenomas were detected in 273 of 3115 procedures in which rectal retroversion was not performed ( $8.8 \% ; P=0.666)$. The relationship between rectal retroversion and rectal adenoma detection did not change when age and sex were accounted for. Colonoscopy variables in the multivariable model are shown in - Table 3. The colonoscopy variables (mean nc-CWT $\geq 10$ minutes, excellent or adequate bowel preparation, intravenous antispasmodic use, and colonoscopists prior screening experience> 300 procedures) were all associated with an increase in adenoma detection with statistically significant odds ratios between 1.10 (95\%CI $1.05-1.16)$ and 1.38 (95\%CI $1.23-1.54)$. Procedures start- 
Table 3 Multivariable logistic regression demonstrating relationships between patient and colonoscopy factors with one or more adenomas, advanced adenomas, and right-sided adenomas as the outcome variables.

\begin{tabular}{|c|c|c|c|c|c|c|}
\hline & $\begin{array}{l}\text { Adjusted OR [ } 95 \% \\
\mathrm{Cl} \text { ] for } \geq 1 \text { adenomas }\end{array}$ & $P$ & $\begin{array}{l}\text { Adjusted OR [ } 95 \% \\
\mathrm{Cl} \text { ] for } \geq 1 \text { advanced } \\
\text { adenomas }\end{array}$ & $P$ & $\begin{array}{l}\text { Adjusted } \mathrm{OR} \text { [ } 95 \% \\
\mathrm{Cl} \text { ] for } \geq 1 \text { right-sided } \\
\text { adenomas }\end{array}$ & $P$ \\
\hline \multicolumn{7}{|l|}{ Sex } \\
\hline Female & 1.00 & & 1.00 & & 1.00 & \\
\hline Male & $1.77[1.68-1.86]$ & $<0.001$ & $1.55[1.46-1.64]$ & $<0.001$ & $1.88[1.76-2.01]$ & $<0.001$ \\
\hline \multicolumn{7}{|l|}{ Age, years } \\
\hline$<62.5$ & 1.00 & & 1.00 & & 1.00 & \\
\hline $62.5-64.9$ & $1.08[1.00-1.16]$ & .048 & $1.03[0.94-1.11]$ & 0.559 & $1.20[1.09-1.32]$ & $<0.001$ \\
\hline $65-67.49$ & $1.17[1.09-1.25]$ & $<0.001$ & $1.15[1.07-1.24]$ & $<0.001$ & $1.22[1.12-1.33]$ & $<0.001$ \\
\hline$\geq 67.5$ & $1.32[1.24-1.40]$ & $<0.001$ & $1.23[1.15-1.31]$ & $<0.001$ & $1.41[1.31-1.52]$ & $<0.001$ \\
\hline \multicolumn{7}{|l|}{ Smoking } \\
\hline Never & 1.00 & & 1.00 & & 1.00 & \\
\hline Ex-smoker & $1.17[1.11-1.23]$ & $<0.001$ & $1.17[1.11-1.24]$ & $<0.001$ & $1.09[1.02-1.16]$ & $<0.001$ \\
\hline Current smoker & $1.61[1.49-1.75]$ & $<0.001$ & $1.34[1.22-1.45]$ & $<0.001$ & $1.57[1.44-1.72]$ & $<0.001$ \\
\hline \multicolumn{7}{|l|}{ Alcohol } \\
\hline No & 1.00 & & 1.00 & & 1.00 & \\
\hline Yes & $1.30[1.24-1.37]$ & $<0.001$ & $1.38[1.30-1.46]$ & $<0.001$ & $1.27(1.18-1.35)$ & $<0.001$ \\
\hline Deprivation group & & & - & & & \\
\hline 1 (most deprived quintile) & 1.00 & & 1.00 & & - & \\
\hline 2 & $1.07[0.99-1.15]$ & 0.102 & $1.09[1.00-1.18]$ & 0.056 & - & \\
\hline 3 & $1.09[1.01-1.17]$ & 0.034 & $1.15[1.06-1.25]$ & 0.001 & - & \\
\hline 4 & $1.10[1.01-1.19]$ & 0.022 & $1.22[1.12-1.33]$ & $<0.001$ & - & \\
\hline 5 (least deprived quintile) & $1.15[1.06-1.24]$ & 0.001 & $1.32[1.21-1.44]$ & $<0.001$ & - & \\
\hline \multicolumn{7}{|l|}{ Hub area } \\
\hline Midlands & 1.00 & & 1.00 & & 1.00 & \\
\hline South & $1.21[1.13-1.31]$ & $<0.001$ & $1.25[1.15-1.35]$ & $<0.001$ & $1.12[1.03-1.23]$ & 0.012 \\
\hline London & $0.99[0.92-1.07]$ & 0.517 & $0.91[0.83-0.99]$ & 0.026 & $1.43[1.30-1.57]$ & $<0.001$ \\
\hline North-East & $1.26[1.17-1.34]$ & $<0.001$ & $1.35[1.25-1.47]$ & $<0.001$ & $1.17[1.06-1.28]$ & 0.002 \\
\hline Eastern & $1.19[1.11-1.27]$ & $<0.001$ & $1.17[1.08-1.26]$ & $<0.001$ & $1.26[1.16-1.37]$ & $<0.001$ \\
\hline \multicolumn{7}{|l|}{ Cecal Intubation } \\
\hline No & 1.00 & & 1.00 & & 1.00 & \\
\hline Yes & $3.71[3.12-4.33]$ & $<0.001$ & $3.34[2.77-4.02]$ & $<0.001$ & $5.55[4.17-74]$ & $<0.001$ \\
\hline \multicolumn{7}{|l|}{ Rectal retroversion } \\
\hline No & - & & 1.00 & & - & \\
\hline Yes & - & & $0.64[0.59-0.70]$ & $<0.001$ & - & \\
\hline \multicolumn{7}{|l|}{ Mean nc-CWT, minutes } \\
\hline$<10$ & 1.00 & & - & & 1.00 & \\
\hline$\geq 10$ & $1.10[1.05-1.16]$ & $<0.001$ & - & & $1.28[1.20-1.36]$ & $<0.001$ \\
\hline \multicolumn{7}{|l|}{ Bowel preparation quality } \\
\hline Inadequate preparation & 1.00 & & 1.00 & & 1.00 & \\
\hline Excellent or adequate & $1.38[1.23-1.54]$ & $<0.001$ & $1.39[1.22-1.57]$ & $<0.001$ & $1.16[1.01-1.33]$ & 0.035 \\
\hline \multicolumn{7}{|l|}{ Hyoscine use } \\
\hline No & 1.00 & & 1.00 & & 1.00 & \\
\hline Yes & $1.29[1.23-1.36]$ & $<0.001$ & $1.29[1.22-1.36]$ & $<0.001$ & $1.22[1.15-1.30]$ & $<0.001$ \\
\hline \multicolumn{7}{|l|}{ Start time of procedure } \\
\hline $08: 00-11.00$ or $14: 00-16: 00$ & 1.00 & & 1.00 & & - & \\
\hline $11: 00-14: 00$ or $16: 00-18: 00$ & $0.94[0.90-0.99]$ & 0.018 & $0.93[0.88-0.98]$ & $<0.001$ & - & \\
\hline \multicolumn{7}{|c|}{ Prior colonoscopist experience in the BCSP (number of procedures) } \\
\hline $0-299$ & 1.00 & & 1.00 & & 1.00 & \\
\hline$\geq 300$ & $1.20[1.11-1.30]$ & $<0.001$ & $1.23[1.13-1.24]$ & $<0.001$ & $1.38[1.22-1.47]$ & $<0.001$ \\
\hline \multicolumn{7}{|l|}{ IV Sedation } \\
\hline Used & 1.00 & & 1.00 & & 1.00 & \\
\hline Not used & $1.06[0.98-1.14]$ & 0.143 & $1.05[0.97-1.14]$ & 0.210 & $1.01[0.93-1.10]$ & 0.866 \\
\hline
\end{tabular}

OR, odds ratio; Cl, Confidence interval; nc-CWT, mean negative complete colonoscopy withdrawal time; BCSP, Bowel Cancer Screening Programme.

Variables with a $P$ value $<0.1$ in univariable analysis were not included.

ing in the second half of a session (11:00 - 14:00 or 16:00-18:00) were associated with a reduction in detection of adenomas and advanced adenomas (OR 0.94, 95\%CI $0.90-0.99[P=0.018]$ and $0.93,95 \%$ CI $0.88-0.98[P<0.001])$ compared with procedures starting between $08: 00$ and $11: 00$ or $14: 00$ and 16:00. Fig.1 demonstrates this relationship along with withdrawal time, bowel preparation quality, and cecal intubation, which do not vary throughout the day.

In univariable analysis, procedures in which no intravenous sedation was used were associated with lower adenoma, advanced 


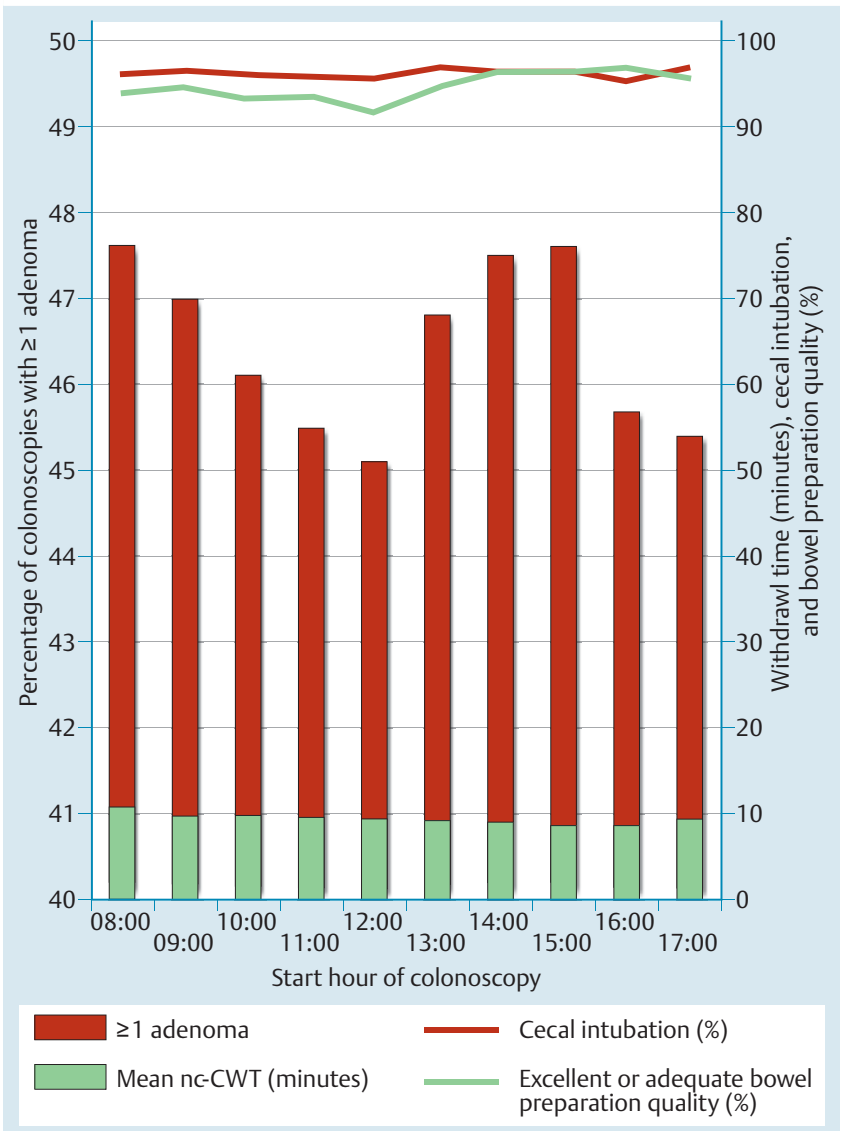

Fig. 1 Relationship between start time of colonoscopy and adenoma detection, withdrawal time, cecal intubation, and bowel preparation quality.

adenoma, and right-sided adenoma detection; however, once other variables were adjusted for in the multivariable models, no significant difference in outcome was seen between the two groups.

The Pearson chi-squared goodness of fit test for each of the final models revealed $P$ values of $0.077,0.264$, and 0.478 for each of the models, respectively.

The ordinal regression model demonstrating the relationship between the total number of adenomas detected at each colonoscopy and patient and colonoscopy factors is shown in $\bullet$ Table 4. The odds ratio refers to the odds of the group having more or less adenomas in total than the reference group.

\section{Discussion}

$\nabla$

This large, national observational study of colonoscopy in a welldefined population found that intravenous antispasmodic drug use, cecal intubation, higher quality bowel preparation, mean withdrawal time of the colonoscopist greater than 10 minutes, earlier start time of the procedure, and prior colonoscopist experience were associated with significantly increased adenoma detection. These factors had similar associations with advanced adenoma detection, right-sided adenoma detection, and total number of adenomas detected. Rectal retroversion was not associated with an increase in rectal adenoma detection. Cecal intubation was strongly associated with increased adenoma detection. Several potential explanations exist: lesions proximal to the point of insertion will have been missed; the cause of the in- complete examination (e.g. poor preparation or diverticulosis) may reduce mucosal visualization; in the context of a malignant stricture the colonoscopist may have reduced motivation to identify or report adenomas; finally, if the examination was incomplete due to poor bowel preparation, the colonoscopist may not look for adenomas as they know a repeat procedure will be required. An alternative approach to this method of analysis would be to exclude incomplete procedures; doing so resulted in minimal change to the outcome of the models but reduced the size of the study population.

Adenomas were less likely to be detected in individuals with inadequate bowel preparation. This corroborates a recent study demonstrating increased missed rates where the bowel preparation was poor [32]. Improving bowel preparation quality is a widely accepted method of improving adenoma detection [14-16].

Rectal retroversion was not shown to increase detection of either adenomas or rectal adenomas. It was associated with a reduction in detection of advanced adenomas throughout the colon. A potential explanation is that rectal retroversion may be less likely to be performed if significant pathology has been detected earlier in the procedure. Although a previous study of 480 screening flexible sigmoidoscopies showed a benefit from rectal retroversion [21], a more recent study showed that rectal retroversion did not detect clinically important neoplasia after careful forwardviewing examination and emphasized the potential harm of the maneuver [22]. The current study supports the conclusion of this latter study that following thorough antegrade inspection of the distal rectum, retroversion should be at the discretion of the colonoscopist.

The current retrospective study appears to support the routine use of intravenous antispasmodic (hyoscine N-butylbromide): its use was associated with a $30 \%$ higher adenoma detection. Its use was also associated with higher detection rates of advanced adenomas, right-sided lesions, and total number of adenomas. It is not clear whether the administration of the antispasmodic is directly responsible for the increase in adenoma detection or whether antispasmodic use is more usual practice of higher performing colonoscopists. Existing literature is conflicting on the role of antispasmodic use during colonoscopy in terms of procedure time and patient comfort [17-20,33]. A randomized controlled trial within a population such as the NHS BCSP would be desirable.

The study identified higher adenoma detection with earlier procedure start time during both morning and afternoon lists. BCSP lists are half-day sessions, limited to four colonoscopies, so time pressure should be minimal. Neither quality of bowel preparation nor withdrawal time accounted for this effect. One possible explanation is that colonoscopist fatigue may be contributing to reduced adenoma detection as the list progresses. It is also possible that colonoscopists choose to ignore the presence of an adenoma to avoid delaying the finish of the list, although we feel that this is unlikely as BCSP colonoscopists are aware that their ADR is under continuous review. Two American studies have demonstrated that polyp detection decreases in afternoon compared with morning colonoscopy and with each subsequent hour of the day $[23,24]$. However, the effect of bowel preparation quality was not accounted for in either of these studies. A recent single-center American study of 20 colonoscopists observed a similar phenomenon of declining polyp detection toward the end of an endoscopist's shift [24]. Further investigation into the potential role of operator fatigue during colonoscopy is required. 


\begin{tabular}{|c|c|c|c|}
\hline & OR & $95 \% \mathrm{Cl}$ & $P$ \\
\hline \multicolumn{4}{|l|}{ Sex } \\
\hline Male & 1.89 & $1.78-1.99$ & $<0.001$ \\
\hline Female & 1.00 & - & - \\
\hline \multicolumn{4}{|l|}{ Age, years } \\
\hline$<62.5$ & 0.75 & $0.70-0.80$ & $<0.001$ \\
\hline $62.5-64.9$ & 0.82 & $0.76-0.88$ & $<0.001$ \\
\hline $65-67.49$ & 0.90 & $0.84-0.96$ & 0.003 \\
\hline$\geq 67.5$ & 1.00 & - & - \\
\hline \multicolumn{4}{|l|}{ Smoking } \\
\hline Never & 0.55 & $0.51-0.60$ & $<0.001$ \\
\hline Ex-smoker & 0.64 & $0.59-0.70$ & $<0.001$ \\
\hline Current smoker & 1.00 & - & - \\
\hline \multicolumn{4}{|l|}{ Alcohol } \\
\hline No & 0.76 & $0.72-0.81$ & $<0.001$ \\
\hline Yes & 1.00 & - & - \\
\hline \multicolumn{4}{|l|}{ Cecal Intubation } \\
\hline No & 0.24 & $0.19-0.27$ & $<0.001$ \\
\hline Yes & 1.00 & - & - \\
\hline \multicolumn{4}{|l|}{ Rectal retroversion } \\
\hline No & 1.34 & $0.82-0.68$ & $<0.001$ \\
\hline Yes & 1.00 & - & - \\
\hline \multicolumn{4}{|l|}{ Mean nc-CWT, minutes } \\
\hline$<10$ & 0.89 & $0.84-0.93$ & $<0.001$ \\
\hline$\geq 10$ & 1.00 & - & - \\
\hline \multicolumn{4}{|l|}{ Bowel preparation quality } \\
\hline Inadequate preparation & 0.70 & $0.63-0.79$ & $<0.001$ \\
\hline Excellent or adequate & 1.00 & & - \\
\hline \multicolumn{4}{|l|}{ Hyoscine use } \\
\hline No & 0.76 & $0.73-0.80$ & $<0.001$ \\
\hline Yes & 1.00 & - & - \\
\hline \multicolumn{4}{|l|}{ Start time of procedure } \\
\hline $08: 00-11.00$ or $14: 00-16: 00$ & 1.08 & $1.03-1.13$ & 0.003 \\
\hline $11: 00-14: 00$ or $16: 00-18: 00$ & 1.00 & - & - \\
\hline \multicolumn{4}{|c|}{$\begin{array}{l}\text { Prior colonoscopist experience in the BCSP, } \\
\text { number of procedures }\end{array}$} \\
\hline $0-299$ & 0.81 & $0.75-0.88$ & $<0.001$ \\
\hline$\geq 300$ & 1.00 & - & - \\
\hline
\end{tabular}

Table 4 Ordinal regression model of the effect of patient and colonoscopy factors on the total number of adenomas detected per procedure.

Variables with a $P$ value $<0.1$ in univariable analysis were not included.

Previous reports on the effect of colonoscopist experience on adenoma detection are conflicting. A number of studies show no relationship or a negative association between increasing experience and adenoma detection [10 - 13]. A study of adenoma detection in a large trial of flexible sigmoidoscopy screening demonstrated that the ADR of some endoscopists increased with experience [34]. The current data suggest that individuals colonoscoped by a colonoscopist who had performed $\geq 300$ colonoscopies in the screening program were 1.2 times more likely to have one or more adenomas than if the colonoscopist had performed $<300$ procedures. These data are of note in light of recent European guidelines that recommend screening colonoscopists perform a minimum of 300 procedures per year [35].

Unsedated colonoscopy comprised $13.1 \%$ of colonoscopies in the study. Two recent American studies have suggested that deeper sedation is associated with increased detection of colonic patho$\operatorname{logy}[25,26]$. Although depth of sedation was not included as a patient variable in the current study, the data demonstrated that high levels of lesion detection were achievable in unsedated patients and that adenoma detection was not reduced in patients undergoing unsedated colonoscopy.

Two recent studies have analyzed patient and colonoscopy factors affecting ADR using multivariable analysis [36,37]. Jover et al. analyzed 4539 colonoscopies in a Spanish trial of screening colonoscopy compared with fecal immunochemical testing [36]. Their statistical approach and findings were similar to those described in our paper; however, potential confounding patient factors were limited to age, sex, and hospital. Adler et al. analyzed 12134 screening colonoscopies in the Berlin Colonoscopy Project [37]. Their statistical approach differed to ours in that their outcome variable was ADR as a continuous variable. Their findings of a positive association of age, sex, and bowel preparation quality are consistent with our findings; however, they did not find an association with withdrawal time, probably explained by the narrower range of mean withdrawal times (6-11 minutes).

Recent studies have drawn attention to the importance of detection of serrated polyps [38]. The current study did not include serrated polyps alone as an outcome measure, although serrated adenomas were included in the adenoma count when detected. Recognition and categorization of serrated polyps has evolved since the dataset was completed in 2009. A recent Dutch study of 1354 patients and five colonoscopists found that increasing withdrawal time was associated with increase in proximal serrated polyp detection [39]. No other colonoscopic factors and no patient factors were demonstrated to be associated with proximal serrated polyp detection, although the relatively small study 
may have been underpowered to demonstrate other relationships.

The current study has a number of limitations. First, data were not available on some notable patient risk factors including family history of CRC and aspirin use. Secondly, this study is retrospective in design and lacks the advantages of a prospective randomized controlled trial. However, the size and breadth of the dataset offset some of these limitations. Thirdly, the indication for all colonoscopies in the study was a positive FOBT. This potentially affects the external validity of the findings outside the context of an FOBT-positive population where the yield of adenomas is considerably higher than in those undergoing primary screening colonoscopy or in the general average-risk population.

A number of the colonoscopy factors included in the current study have also been demonstrated to be associated with adenoma detection in nonscreening populations [40]. It is likely that many of the findings of the current study would also apply to adenoma detection in the general population undergoing colonoscopy. The clinical objective of colonoscopy outside of a screening program, however, may not be cancer or adenoma detection. In summary, this large study has demonstrated the importance of technical colonoscopy factors in determining adenoma detection during colonoscopy. The study identified colonoscopist-modifiable factors (cecal intubation, mean withdrawal time, bowel preparation quality, use of intravenous antispasmodic, and start time of the colonoscopy) that can help to optimize adenoma detection and improve the quality of colonoscopy. These factors affect not only the risk of detecting one or more adenomas but also advanced adenomas, right-sided adenomas, and total number of adenomas.

\section{Competing interests: None}

Institutions

${ }^{1}$ Tees Bowel Cancer Screening Centre, University Hospital of North Tees, Stockton-on-Tees, UK

${ }^{2}$ Institute of Health and Society, Newcastle University, Newcastle-upon-Tyne, UK

South of Tyne Bowel Cancer Screening Centre, South Tyneside District Hospital, South Shields, UK

${ }^{4}$ School of Medicine, Pharmacy and Health, Durham University, Stockton-onTees, UK

Northern Region Endoscopy Group, UK

${ }^{6}$ Epidemiology Unit, Richard Doll Building, Oxford, UK

Cancer Screening Evaluation Unit, Institute of Cancer Research, University of London, Sutton, London, UK

${ }^{8}$ NHS Cancer Screening Programmes, Sheffield, UK

\section{Acknowledgments}

We thank all Bowel Cancer Screening Programme Centres for their assistance with data collection. We acknowledge database analysts, Neal Lilly and Kate Bruce.

This paper was presented as a poster at the 2011 British Society of Gastroenterology Annual General Meeting, Birmingham (UK) and as an oral presentation at the 2011 Digestive Disease Week, Chicago (Illinois, USA).

\section{References}

1 Office for National Statistics Mortality Statistics. Cause. England and Wales 2008. London: TSO; 2010

2 Morson B. President's address: the polyp-cancer sequence in the large bowel. Proc R Soc Med 1974; 67: 451-457

3 Rex DK, Petrini JL, Baron TH et al. Quality indicators in colonoscopy. Gastrointest Endosc 2006; 63: 16-28
4 Kaminski MF, Regula J, Krasewska E et al. Quality indicators for colonoscopy and the risk of interval cancer. N Engl J Med 2010; 362: 1795 1803

5 Lieberman DA, Prindiville S, Weiss DG et al. Risk factors for advanced colonic neoplasia and hyperplastic polyps in asymptomatic individuals. JAMA 2003; 290: 2959-2967

6 Anderson JC, Attam R, Alpern Z et al. Prevalence of colorectal neoplasia in smokers. Am J Gastroenterol 2003; 98: 2777 - 2783

7 Reid ME, Marshall JR, Roe D et al. Smoking exposure as a risk factor for prevalent and recurrent colorectal adenomas. Cancer Epidemiol Biomarkers Prev 2003; 12: 1006 - 1011

8 Anderson JC, Alpern Z, Sethi G et al. Prevalence and risk of colorectal neoplasia in consumers of alcohol in a screening population. Am J Gastroenterol 2005; 100: 2049-2055

9 Martinez ME, McPherson RS, Annegers JF et al. Cigarette smoking and alcohol consumption as risk factors for colorectal adenomatous polyps. J Natl Cancer Inst 1995; 87: $274-279$

10 Chen SC, Rex DK. Endoscopist can be more powerful than age and male gender in predicting adenoma detection at colonoscopy. Am J Gastroenterol 2007; 102: 856-861

11 Barclay RL, Vicari JJ, Doughty AS et al. Colonoscopic withdrawal times and adenoma detection during screening colonoscopy. N Engl J Med 2006; 355: 2533 - 2541

12 Simmons DT, Harewood GC, Baron TH et al. Impact of endoscopist withdrawal speed on polyp yield: implications for optimal colonoscopy withdrawal time. Aliment Pharmacol Ther 2006; 24: 965 -971

13 Lee TJW, Blanks RG, Rees CJ et al. Longer mean colonoscopy withdrawa time is associated with increased adenoma detection: evidence from the Bowel Cancer Screening Programme in England. Endoscopy 2013; 45: $20-26$

14 Harewood GC, Sharma VK, de Garmo P. Impact of colonic preparation quality on detection of suspected colonic neoplasms. Gastrointest Endosc 2003; 58: 76-79

15 Froelich F, Wietlisbach V, Gonvers JJ et al. Impact of colonic cleansing on quality and diagnostic yield of colonoscopy: the European Panel of Appropriateness of Gastrointestinal Endoscopy European Multicentre Study. Gastrointest Endosc 2005; 61: 378 - 384

16 Belsey J, Epstein 0 , Heresbach $D$. Systematic review: oral bowel preparation for colonoscopy. Aliment Pharmacol Ther 2007; 25: 373 - 384

17 de Brouwer EJ, Arbouw ME, van der Zwet WC et al. Hyoscine N-butylbromide does not improve polyp detection during colonoscopy: a double-blind, randomized, placebo-controlled, clinical trial. Gastrointest Endosc 2012; 75: 835-840

18 Mui L, Enders KWN, Kang-chung $C$ et al. Randomized, double-blinded, placebo-controlled trial of intravenously administered hyoscine n-butyl bromide in patients undergoing colonoscopy with patient controlled sedation. Gastrointest Endosc 2004; 59: 22-27

19 Lee JM, Cheon JH, Park JJ et al. Effects of hyoscine n-butyl bromide on the detection of polyps during colonoscopy. Hepatogastroenterology 2010; $57:$ : $90-94$

20 Corte C, Dahlenburg L, Selby S et al. Hyoscine butylbromide administered at the cecum increases polyp detection: a randomized doubleblind placebo-controlled trial. Endoscopy 2012; 44: 917-922

21 Hanson JM, Atkin WS, Cunliffe WJ et al. Rectal retroflexion: an essentia part of lower gastrointestinal endoscopic examination. Dis Colon Rectum 2002; 45: 1120-1121

22 Saad A, Rex DK. Routine rectal retroflexion during colonoscopy has a low yield for neoplasia. World J Gastroenterol 2008; 14: 6503-6505

23 Chan MY, Cohen H, Spiegel BMR. Fewer polyps detected by colonoscopy as the day progresses at a veteran's administration teaching hospital. Clin Gastroenterol Hepatol 2009; 7: 1217-1223

24 Long MD, Martin C, Sandler RS et al. Reduced polyp detection as endoscopy shift progresses: experience with screening colonoscopy at a tertiary-care hospital. J Clin Gastroenterol 2011; 45: 253-258

25 Radaelli F, Meucci G, Sgroi G et al. Technical performance of colonoscopy: the key role of sedation/analgesia and other quality indicators. Am J Gastroenterol 2008; 103: 1122-1130

26 Wang A, Hoda KM, Holub JL et al. Does level of sedation impact detection of advanced neoplasia. Dig Dis Sci 2010; 55: 2337-2343

27 Logan RF, Patnick J, Nickerson C et al. Outcomes of the Bowel Cancer Screening Programme (BCSP) in England after the first 1 million tests. Gut 2012; 61: 1439-1446

28 Lee TJW, Rutter MD, Blanks RG et al. Colonoscopy quality measures: experience from the NHS Bowel Cancer Screening Programme. Gut 2012; 61: $1050-1057$ 
29 Lee TJW, Clifford GM, Rajasekhar P et al. High yield of colorectal neoplasia detected by colonoscopy following a positive faecal occult blood test in the NHS Bowel Cancer Screening Programme. J Med Screen 2011; 18: $82-86$

30 Chilton A, Rutter MD. BCSP Quality Assurance Guidelines for Colonoscopy. Available at: http://www.cancerscreening.nhs.uk/bowel/publications/nhsbcsp06.html

31 Department of Communities and Local Government. Indices of Deprivation. 2007: Available at: http://webarchive.nationalarchives.gov.uk/ +/http:/www.communities.gov.uk/communities/neighbourhoodrenewal/deprivation/deprivation07/

32 Chokshi RV, Hovis CE, Hollander T et al. Prevalence of missed adenomas in patients with inadequate bowel preparation on screening colonoscopy. Gastrointest Endosc 2012; 75: 1197-1203

33 Saunders BP, Williams CB. Premedication with intravenous antispasmodic speeds colonoscope insertion. Gastrointest Endosc 1996; 43: $209-211$

34 Atkin $W$, Rogers $P$, Cardwell $C$ et al. Wide variation in adenoma detection rates at screening flexible sigmoidoscopy. Gastroenterology 2004; 126: $1247-1256$
35 Segnan N, Patnick J, von Karsa L et al. European guidelines for quality assurance in colorectal cancer screening and diagnosis- first edition. Luxemburg: Publications Office of the European Union; 2011

36 Jover R, Zapater P, Polania E et al. Modifiable endoscopic factors that influence the adenoma detection rate in colorectal cancer screening colonoscopies. Gastrointest Endosc 2013; 77: 381 - 389

37 Adler A, Wegscheider K, Lieberman $D$ et al. Factors determining the quality of screening colonoscopy: a prospective study on adenoma detection rates from 12134 examination (Berlin colonoscopy project 3 , BECOP-3). Gut 2013; 52: 236-241

38 Liang J, Kalady MF, Church J et al. Serrated polyp detection rate during colonsocpy. Colorectal Dis 2012; 14: 1323-1327

39 De Wijkerslooth TR, Stoop EM, Bossuyt PM et al. Differences in proximal serrated polyp detection among endoscopists are associated with variability in withdrawal time. Gastrointest Endosc 2013; 77: 617 623

$40 \operatorname{Rex} \mathrm{DK}$. Colonoscopic withdrawal technique is associated with adenoma miss rates. Gastrointest Endosc 2000; 51: $33-36$ 